\title{
One-step Preparation of Robust Superhydrophobic Foam for Oil/Water Separation by Pulse Electrodeposition
}

Yonghui Zhang ${ }^{\mathrm{a}, \mathrm{b}}$, Jiangwen Liu ${ }^{\mathrm{a}, \mathrm{b},{ }^{*} \text {, Ligeng Ouyang }}{ }^{\mathrm{a}, \mathrm{b}}$, Jiaming $\mathrm{Li}^{\mathrm{a}, \mathrm{b}}$, Guie Xie ${ }^{\mathrm{c}, *}$, Yinyin Yan ${ }^{\mathrm{a}, \mathrm{b}}$, Can Weng ${ }^{\mathrm{d}}$ ${ }^{a}$ State Key Laboratory of Precision Electronic Manufacturing Technology and Equipment, Guangdong University of Technology, Guangzhou 510006, PR China

${ }^{\mathrm{b}}$ Guangzhou Key Laboratory of Nontraditional Machining and Equipment, Guangdong University of Technology, Guangzhou 510006, PR China

'KingMed School of Laboratory Medicine, Guangzhou Medical University, Guangzhou510182, P.R. China

${ }^{\mathrm{d} C o l l e g e ~ o f ~ M e c h a n i c a l ~ a n d ~ E l e c t r i c a l ~ E n g i n e e r i n g, ~ C e n t r a l ~ S o u t h ~ U n i v e r s i t y, ~ C h a n g s h a ~ 410083, ~ C h i n a ~}$

*Corresponding author.E-mail address: fejwliu@scut.edu.cn (J. Liu); guier2003@126.com (G. Xie).
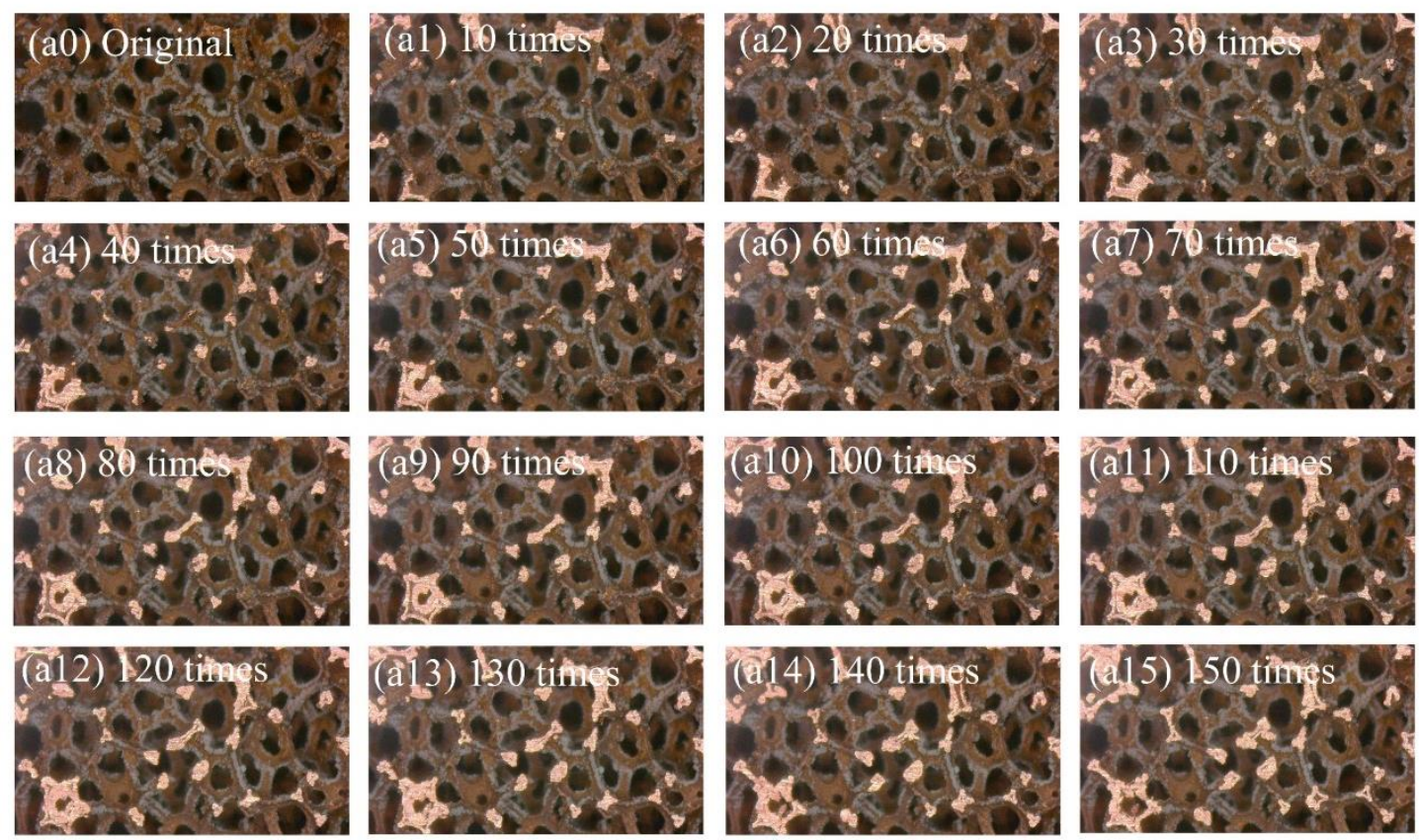

Figure S1. The surface topography of the sample after 150 cycles of abrasion test.

Table S1. Wear coefficient $\mathrm{f}$ under different cycles of wear.

\begin{tabular}{ccccccccc}
\hline Abrasion cycles & 0 & 10 & 20 & 30 & 40 & 50 & 60 & 70 \\
\cline { 2 - 9 } & 80 & 90 & 100 & 110 & 120 & 130 & 140 & 150 \\
\hline$f$ & 0 & $3.67 \%$ & $4.74 \%$ & $6.24 \%$ & $6.8 \%$ & $7.55 \%$ & $8.43 \%$ & $9.43 \%$ \\
& $9.62 \%$ & $10.39 \%$ & $10.87 \%$ & $11.01 \%$ & $11.45 \%$ & $11.88 \%$ & $12.24 \%$ & $12.60 \%$ \\
\hline
\end{tabular}



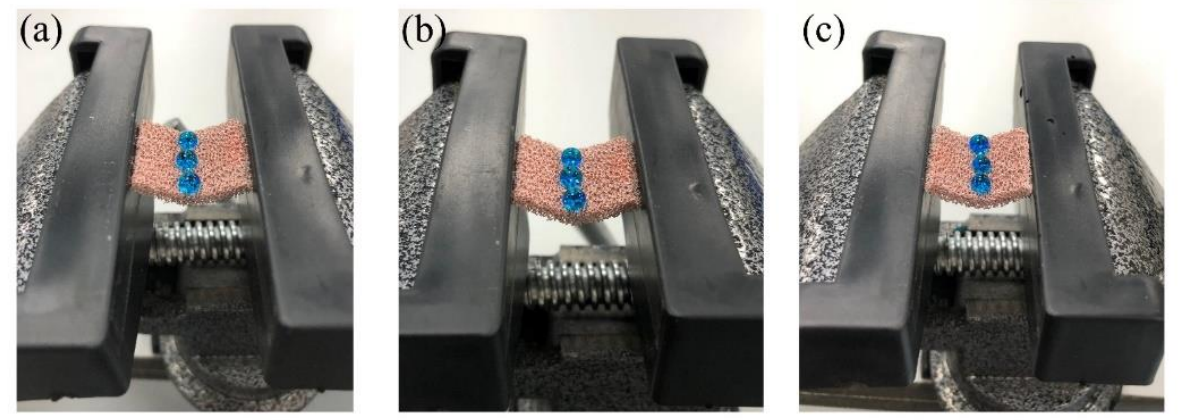

Figure S2. The shape of water droplets under different bending times. (a) Bend 1time, (b) Bend 5 times, (c) Bend 10 times.
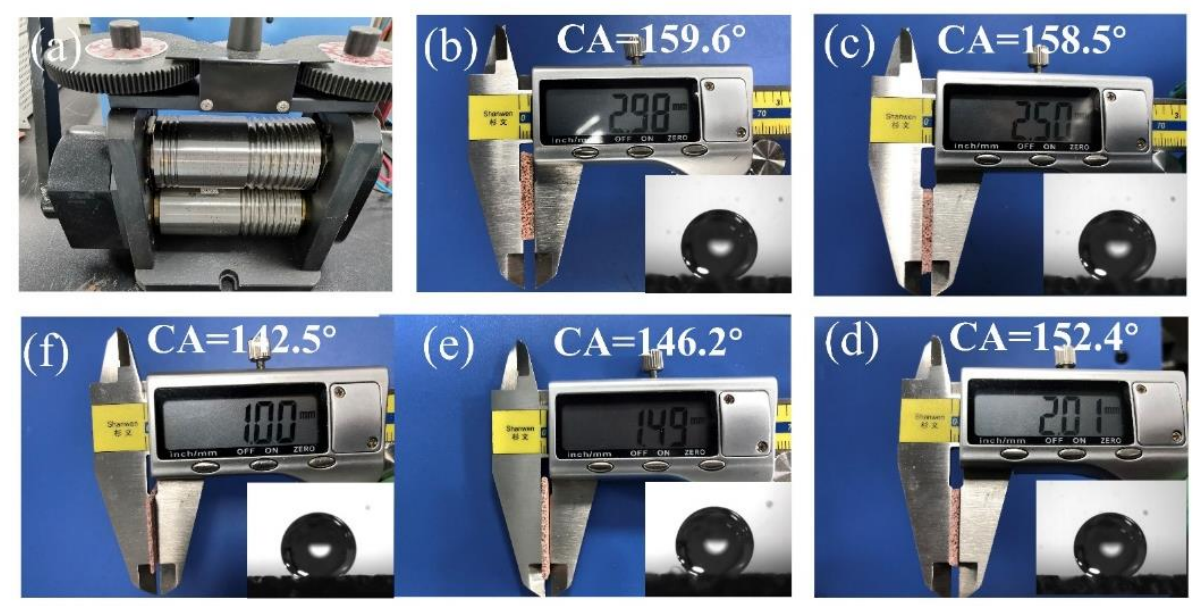

Figure S3. Static contact angle under different tablet thickness.
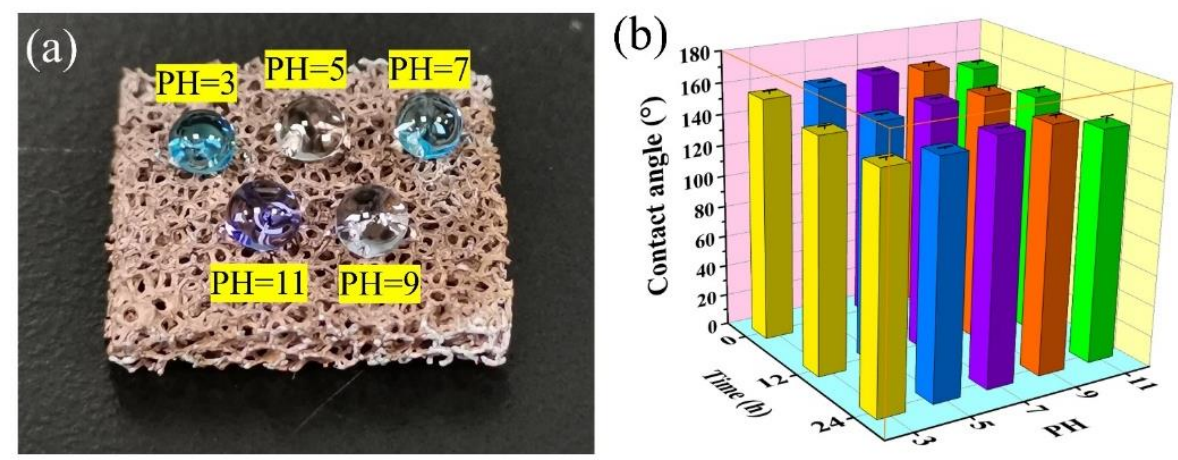

Figure S4. (a) Static characteristics of water droplets at different $\mathrm{pH}$ values on the surface of the sample, (b) 3D histograms of static contact angles of the sample immersed in solutions of different $\mathrm{pH}$ values for different times. 


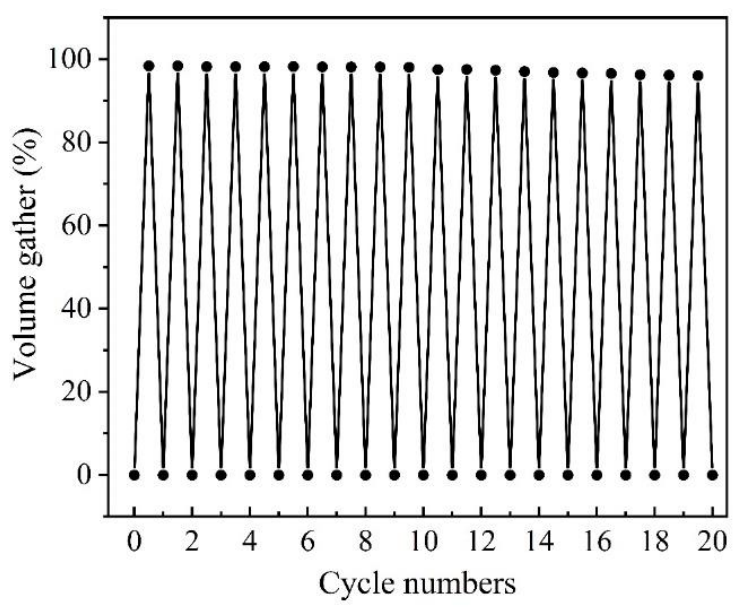

Figure S5. Different separation efficiencies of SCF on different cycle times

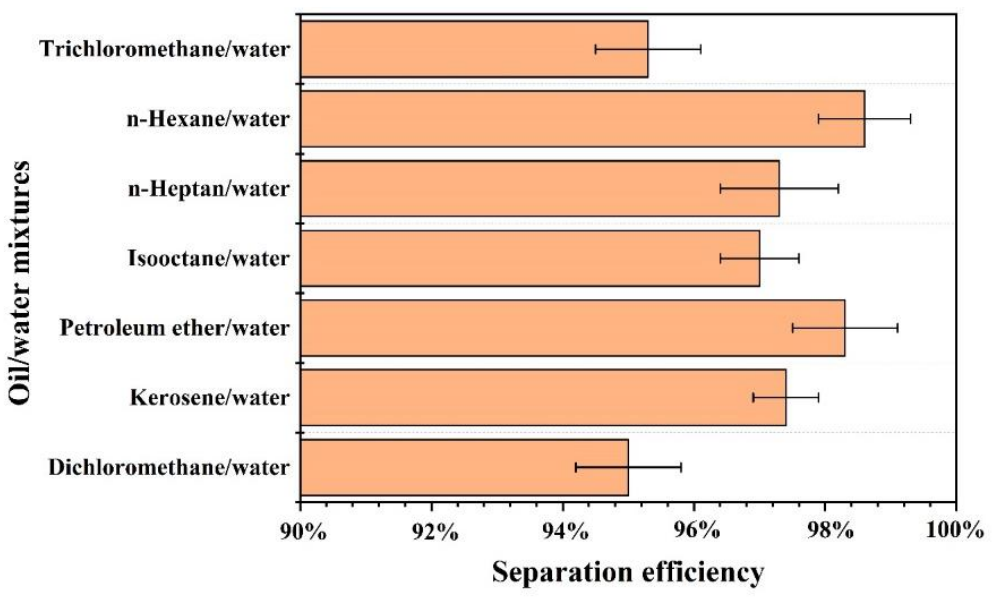

Figure S6. The separation efficiency of samples in different oil/water mixtures.

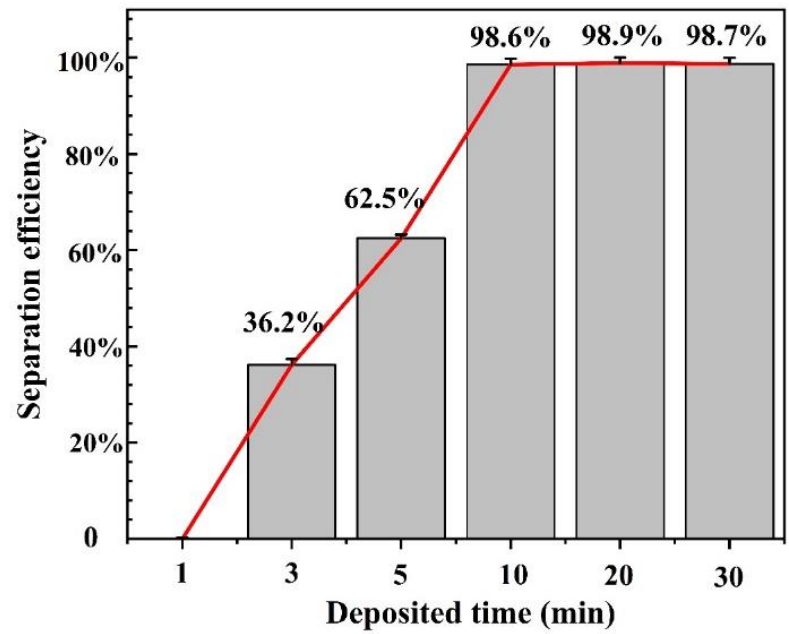

Figure S7. Separation efficiency of foamed copper with different electrodeposition time in n-hexane/water mixture. 

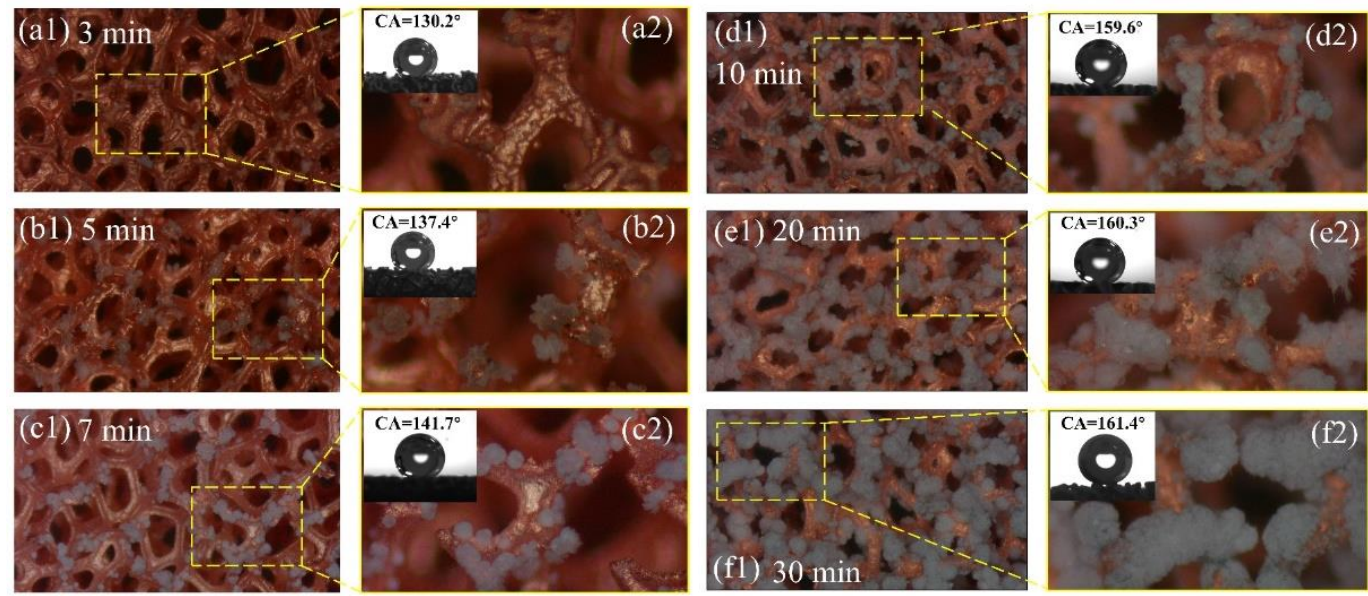

Figure S8. Surface morphologies and static water contact angles of foamed copper at different electrodeposition times.
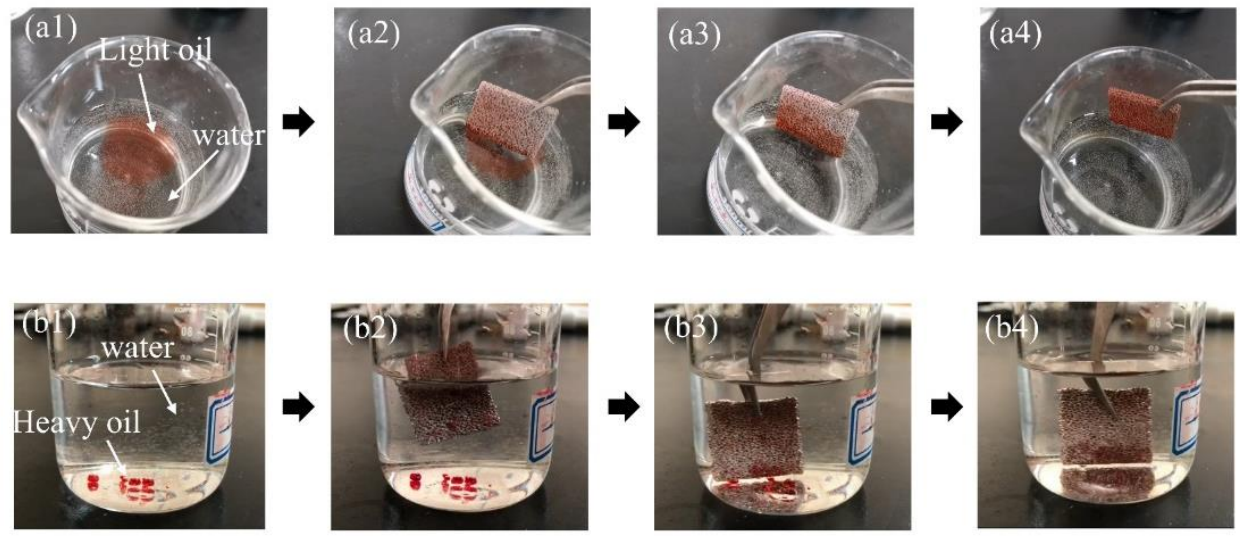

Figure S9. The adsorption process of SCF in the mixture of light oil and heavy oil.

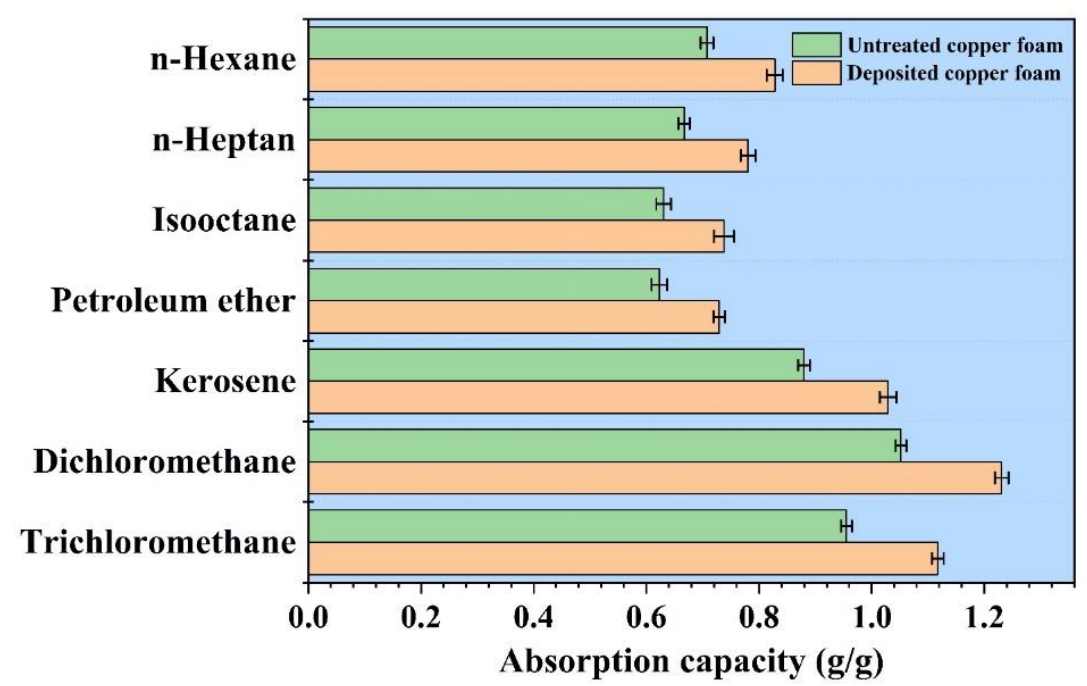

Figure S10. Adsorption capacity of the sample for different oils for untreated copper foam and deposited copper foam. 